DOI: https://doi.org/10.3126/jbssr.v5i2.35236

\title{
The Stock Market's Reaction to Unanticipated Catastrophic Event
}

\author{
Dipendra Karki í Event
}

Article History

Received 8 Oct 2020

Reviewed 29 Nov 2020

Revised 11 Dec.2020

Plagiarism Checked

13 Dec. 2020

Revised 15 Dec 2020

Accepted 23 Dec 2020

Keywords

Catastrophic event, earthquake, stock market

Journal of Business

and Social Sciences

Research (ISSN: 2542-

2812). Vol V, No. 2, Dec

2020

\section{Abstract}

Several factors influence the stock market; they trigger market over-or under-reactions. The paper aims to identify the effect of a major catastrophic event on stock returns. For this, daily data of stock market indices was used with a total of 210 observations and the effect of catastrophic event, Nepal Earthquake 2015, was tested using the method of event analysis for different event windows. The catastrophic event did not affect stock returns significantly and was resilient to earthquake-induced shocks. The event window $(+2,+10)$ shows the higher and positive abnormal returns which depicts that the market has recovered from the shock in as many as three days. The study shows that stock market in Nepal is semi-strongly inefficient.

\section{Introduction and Study Objectives}

In the past 23 years, the stock market of Nepal has experienced many booms and busts. The NEPSE has recently rebounded after the Covid-19 pandemicinduced fall of nearly 442 points with huge sell-off from March 1, 2020 reaching the lowest point 1188.70 on June 29, 2020 and the market has been bullish from there, breaking one record after another. Which factors are responsible for these volatility shifts? In this or that way, each individual particularly related to the stock market, attempts to find an answer to these queries. Graham (1973) noted in this respect that stocks would be good or bad in future because the firms behind them have done good or bad. However, prices in some markets show common movements that are hard to explain by fundamental movements (Watanabe, 2008). What else would change stock prices over time if the fundamental values are not vital? Although various studies have been carried out, most of the current literature underlying theoretical constructs, defines the relation between

${ }^{1}$ Mr. Karki holds an MPhil degree from Nepal and teaches Finance-related subjects in different university colleges. He is a Ph.D. scholar at Kathmandu University School of Management. His email is: dipendra.karki@kusom.edu.np 
macroeconomic volatility and stock market prices.

Fundamental and macroeconomic variables are not the only factors of stock volatility. There are more other pieces of information, which can make investors react to market immediately. Sentiment of investors, macroeconomic, and monetary variables have some impact on stock prices (Karki, 2017). Besides, the unanticipated news and events in financial markets also have an impact on stock returns. For instance, political risks (Beaulieu et al., 2006) and natural calamities; avalanche, flood, fire, epidemic \& earthquake (Lamb, 1998; Carter \& Simkins, 2004; Ramjah, 2013). Papadakis (2006) has concluded that the earthquake generated negative abnormal returns. This study examines whether this piece of findings also valid to our stock market. So, the occurrence of devastating earthquake Nepal-2015 is the considerable catastrophic event of the study.

Event description. On 25 April 2015, a 7.6 magnitude earthquake (as reported by the National Seismological Centre, Nepal) hit Barpak in Gorkha District, approximately $76 \mathrm{~km}$ northwest of Kathmandu, followed by many aftershocks, including one measuring 6.8 magnitude, which struck the epicentre near Mount Everest on 12 May. (National Reconstruction Authority: NRA, 2016). The devastating earthquake led to the tremendous loss of human capital, physical resources, infrastructure and natural resources. 8,891 people have been killed and 22,302 wounded so far. 608,155 residential buildings have been demolished, while 298,998 have been partially damaged. Likewise, 2,687 government buildings were collapsed completely and 3,776 were partially damaged. Besides, the earthquake struck 743 historically and archaeologically invaluable heritage sites/monuments, causing 133 completely collapsed, 95 partially collapsed and 515 partially damaged. It has been estimated that assets equal to Rs. 706.5 billion have been damaged/destroyed. It has been estimated to have damaged/ destroyed properties equivalent to Rs. 706.5 billion (Post Disaster Needs Assessment: PDNA, 2015).

The theory of market efficiency (Fama, 1970) assumes that the market easily impounds any publicly accessible information. In the semi-strong form of market efficiency, the announcement of new information instantly affects investors' psychology, in general, and investors cannot use historical prices and published information to gain unusual returns (Syed \& Bajwa, 2018). Thus, any new announcement; including mergers and acquisitions, dividend and earnings releases, major policy changes, unexpected political declarations, business growth, macro-economic changes, natural disasters, or pandemic is immediately responded by the stock market.

However, the higher variations in stock prices have awakened several questions regarding the pricing efficiency of the stock market. It is only new information that moves prices, and particularly new and unexpected information, and yet many studies only analyse announcements that have a predictable component. Researchers usually pick a proxy for the anticipated portion of the news announcement and then examine the market's response to the unanticipated 
portion of the announcement (Brooks et al., 2003). Empirical evidence indicates that the extreme version of the theory of market efficiency is not true. This research aims to identify the degree of market efficiency measured by the speed at which stock prices are adjusted for new and unanticipated information.

\section{Literature Review}

Fama (1970)-led Efficient Market Hypothesis (EMH), believed that securities markets were entirely capable of reflecting stock-specific and stock market data as a whole. The accepted view is that when data arises, the information is quickly distributed and is embedded in securities prices without delay. Therefore, neither technical analysis nor even fundamental analysis helps investors to pick "undervalued" stocks in order to gain excess returns than generated by keeping an arbitrarily chosen portfolio of comparably risky individual stocks. "weak", "semistrong" and "strong" are the three main types of market efficiency. Evidence exists for and against weak and semi-strong EMHs, although strong evidence exists against strong EMHs. The market is semi-strongly efficient when the stock prices represent historical information and all publicly accessible information. Studies of the semi-strong form of the hypothesis of efficient markets may be descried as tests of the pace at which prices are adjusted for new information. The event study is the principal research tool in this field. Different forms of disasters were studied in the past using event study methods.

The effect of the Three Mile Island nuclear disaster on the stock return of public utilities was examined by Hill and Schneeweis (1983). Their study indicates that the influence of the event was lower for non-nuclear firms than on nuclear-based firms. Barrett et al. (1987) examined the stock market reaction on the total of 78 fatal commercial aircraft crashes from January 1962 to December 1985. The analysis showed that the stock price declined dramatically just one full day after the event. Though the accident occurs in a distant geographic region, the market tends to assimilate the new information easily. Shelor et al., (1990) analysed the effect of the California earthquake on the valuation of real estate firms. The results show that the earthquake conveys valuable new market information, which reflects statistically significant negative stock returns for the companies in the area affected by the earthquake. The earthquake had usually not impacted real-estate companies in other countries. Kalra et al. (1993) analysed the market reaction of the United States to the nuclear catastrophe in Chernobyl. According to the report, utility investors correctly interpreted Chernobyl as a new era for U.S. nuclear power, and the stock market soon realised its effects for utilities' stocks.

The study conducted by Blose et al. (1996) on the Challenger crash presented a substantial negative abnormal return on NASA contractor stocks on the day of the explosion, and any infectious impact was restricted to a small group of NASA contractors. Angbazo and Ranga (1996) analysed the effect of Hurricane and a consequent adjustment in the regulatory climate on 48 publicly-traded propertyliability insurers' stock prices. They showed that because they greatly impacted 
most insurers, Hurricane and the related regulations had a sector-wide contagion impact, irrespective of whether these firms had any damaging exposure in the impacted areas.

The study results by Bosch et al. (1998) showed strong evidence that the stock market imposes losses of equity on companies after the publication of negative information on product safety, including airlines involved in crashes. However, air accident events have shown little to no sign of effects on other businesses to date, and the origins of the crash airline' stock reaction remains at issue. Lamb (1998) has examined the market efficiency around hurricanes. The observation reveals that, based on their degree of exposure to damages, the stock market was able to discriminate against the magnitude of the hurricanes and property and casualty companies. Kramer and Hyclak (2002) analysed the influence of strikes on the capital market. They found that the declaration of a strike information had statistically significant negative impacts on the total average returns on the hit firms' stock market. Simultaneously, the declaration of a strike had major positive effects on abnormal accumulated returns (CAR) of non - struck competitors in the same industries. Maloney and Mulherein (2003) presented evidence for price discovery speed and precision by observing the stock returns and the amount of trade following the Challenger space shuttle crash. They showed that the price discovery occurred without significant trade gains, and during a trading halt of the business responsible for the defective part, much of the price discovery occurred. Carter and Simkins (2004) studied the reaction of airline stock prices after the September 11 attacks. Their research supported the theory of fair pricing and disclosed the disparity between various airline firms in the stock market.

Earthquake is an unanticipated and unpredictable event. Event analysis conducted by Papadakis (2006) concerns the output of the four stocks (i.e. PC manufacturers-Dell computer, Gateway, Compaq and IBM) after the September 21, 1999 Taiwan earthquake. After sudden component price rises and reduced in share prices, the study found lower profitability. It showed that the stock market responds instantly after the event. Ramiah (2013) analysed the effects of the tsunami of Boxing Day 2004 on world financial markets. The author did not notice any substantial effect on market returns of the equity portfolios, i.e. the tsunami had a marginal effect, by analysing 12 countries that witnessed the natural disaster. The tsunami and market share movements, in other words, had no clear correlation between each other. Furthermore, the study found only marginal improvements in returns by computing it for five days after the event, to await market delays. Any major effect on portfolios has, therefore not been reported at all. However, a growing and vast array of literature has challenged the efficient market hypothesis. Scholars argue that behavioural finance is indeed important to complement the other wider perspectives of social science. For instance, Malkiel (2013) argued on the efficient market hypothesis and claimed that pricing appraisal is not always ideal, and the market has made some errors due to the biases of market participants. 
In Nepalese perspective, Dangol (2008) analysed the Nepalese stock market's response to unexpected political events using the technique of event analysis. His research covered the period from 2001 to 2006 . He found that political events generating good (bad) news produce positive (negative) returns in the post-event cycle. Zakaria and Aziz (2019) analysed in a recent survey, based on the efficient market hypothesis $(\mathrm{EMH})$ the impact of unpredictable political events on Saudi stock market returns. Their findings illustrated that in the beginning the Saudi Bourse had reacted to this case and tried to absorb the information received. The market does not seem to have received the relevant news rapidly or explicitly. Therefore, the data flowing from traders was not available for investment at the same level and period. Therefore, the Saudi stock market is described as a weak-form market (inefficient). In summary, the researchers have agreed that stock prices are driven by unpredictable events.

The conceptual framework of the study based on literature review is presented as follows:

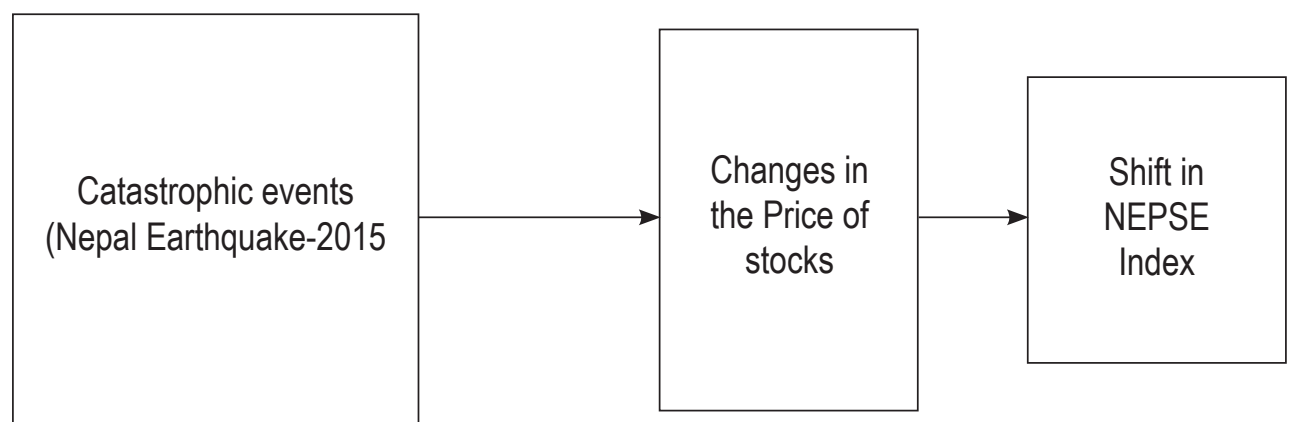

Figure 1: Conceptual Framework of the Study

\section{Research Methods}

The event analysis is more rigorously used in finance to identify the type of market efficiency.

\subsection{Research Design}

Causal comparative and descriptive research designs are used to deal with a catastrophic event affecting stock prices in Nepal. This research paradigm fits the positivist approach. This model suggests, from an ontological point of view, a single universal reality (Jennings, 2001). It studies of the nature of existence.

\subsection{Nature and Sources of Data}

Secondary data from Nepal Stock Exchange Ltd. (NEPSE), are collected for daily stock prices. Data period covers from $15^{\text {th }}$ June 2014 to $7^{\text {th }}$ June, 2015 with total of 210 days data. The data were classified into pre-event and post-event period. Pre-event consisted the 200 days data from beginning period to the just 
one day ahead of event occurrence (i.e., $25^{\text {th }}$ of April, 2015). A Dummy variable (D) was used to represent the event that takes value 1 for devastating event day, 0 otherwise

\subsection{Event Analysis}

Any event's economic effect can be measured with a relatively short time frame of security prices (MacKinlay, 1997). The study determines if there is a "abnormal" stock returns due to the occurrence of an unexpected event. It may derive the significance of the event from this determination. However, as suggested by McWilliams and Siegel (1997) the inference of significance depends on the following assumptions:

(1) The efficient markets exist,

(2) There is no anticipation of the event, and

(3) The event windows bear no confounding effects.

The study also tests the market efficiency using the catastrophic event (earthquake) happening in the country and its impact on stock prices. The estimated period for such purposes begins 200 days prior and ends 21 days before the event date (or $t=-200$ to $t=-21$ ). The estimation duration used in this study complies with earlier literature of the responses of the stock market (Bosch \& Hirchey, 1989; Hovav \& John, 2003). For the analysis of the events, the sample consisted of six different events for 21 days (i.e. -10 days to +10 days) periods (Cheng \& Leung, 2006, as cited in Dangol, 2008). These six event periods, also shown in figure 2 , are as under:
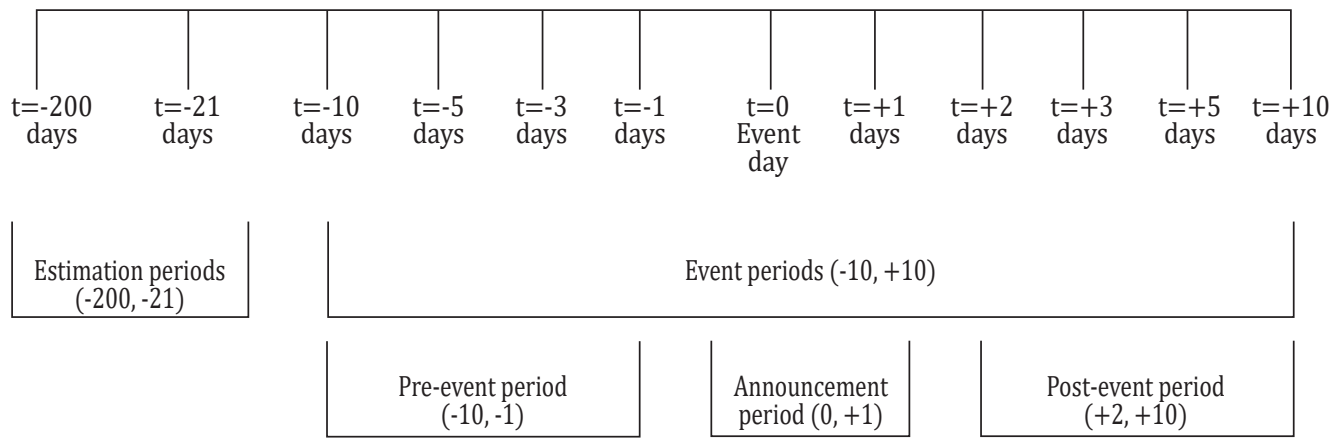

Note. The figure shows the estimation periods, event periods as pre-event period, announcement period and post-event period.

Figure 2: The Parameter Estimation and Event Period

(1) 10 days before the announcement of the event, t-10, to 1 day before the announcement day (i.e. day $t=-10$ to $t=-1$ );

(2) Event day $(t=0)$ to 10 days then the event day $(t+10)$;

(3) 2 days after the event $(t+2)$, to 10 days then the event day $(t+10)$; 
(4) 10 days before the event $(t-10)$ to 10 trading days following the event happening day $(t+10)$;

(5) 5 days before the event $(t-5)$ to 5 days next the event day $(t+5)$; and

(6) 3 days before the announcement $(t-3)$ to 3 days following the event day $(t+3)$. Day $t=0$, is the event day or announcement date of new information.

i) Test of Homogeneity of Variance: Nepal earthquake-2015 characterised as a catastrophic event, is a dummy component. The date for the event $\left(25^{\text {th }}\right.$ April, 2015 ) is numbered " 1 " otherwise " 0 ". This analysis uses stock market indices as the dependent variable to assess whether or not the event influences stock returns. NEPSE Index returns were measured for prior and post event. We use percentage stock returns to address the unit root problem, which makes data stationary.

$$
\mathrm{SR}_{\mathrm{t}}=\frac{\mathrm{NI}_{\mathrm{t}}-1 \mathrm{NI}_{\mathrm{t}-1}}{\mathrm{NI}_{\mathrm{t}-1}}
$$

Where; $\mathrm{SR}_{\mathrm{t}}$ is the stock returns, $\mathrm{NI}_{\mathrm{t}}$ is the Nepse index present day returns and $\mathrm{NIt}_{-1}$ is the prior day index returns

Fama (1991) also conducted event analysis to access the impact of publicly accessible information on stock yields. The analysis evaluates the mean stock yields on prior and post event or any publicly accessible information. Independent t-tests were used for this purpose since they consist of two different data classes, i.e. data from pre-events and data from post-events.

Our study uses Levene's test (Levene, 1960) to verify whether k samples have the same variances. The results are homoscedastic when variances are similar and heteroscedastic when variances are different. The events are considered to have a substantial effect on stock returns if the variances between the groups are not equal.

ii) Dummy Variable Regression Model: Regression modelling (OLS) is the basic method used to fit typical stock return as a function of overall market results during the event period. The method used to compute the abnormal return is based on the dummy variable regression model, which is widely used to assess the impact of events on market performance (Gujarati et al., 2012):

$$
\mathrm{SR}_{\mathrm{it}}=\alpha_{\mathrm{i}}+\beta_{\mathrm{i}} \mathrm{D}_{\mathrm{it}}+\mathrm{e}_{\mathrm{it}}
$$

Where,

$\mathrm{SR}_{\mathrm{it}}=$ the stock return on event $i$ on day $t .=\frac{\text { Price }_{i t}-\text { Price }_{\mathrm{it}-1}}{\text { Price }_{\mathrm{it}-1}}$
$\mathrm{D}_{\mathrm{it}}=$ the Catastrophic event dummy

(takes value 1 if event happens, 0 otherwise)

$\alpha_{i}, \beta_{i}=$ intercept \& slope coefficients to be accessed.

$\mathrm{e}_{\mathrm{it}}=$ stochastic error for stock return on event i on period $t$. 
The model is estimated for each event windows considered in the study.

iii) Estimation of Abnormal Returns: The basic notion of an event study is to identify abnormal returns over the benchmark returns, approximated by an index. Capital Asset Pricing Model (CAPM; $R_{i}=R_{f}+\beta\left(R_{m}-R_{f}\right)$ ) is usually used in the event analysis as a parameter for estimating expected returns. However, our analysis uses the running average approach to measure the estimated returns. Since we consider the market index, the study uses mean adjusted returns method proposed by Brown and Warner (1985) for day-to-day excess stock returns for each event as the abnormal returns as:

$$
\mathrm{AR}_{\mathrm{s}, \mathrm{t}}=\mathrm{R}_{\mathrm{s}, \mathrm{t}}-\mathrm{E}\left(\overline{\mathrm{R}}_{\mathrm{s}}\right)
$$

Where, $A R_{s, t}$ is the excess return for stock market index $\mathrm{s}$ at time $\mathrm{t}, R_{\mathrm{s}, t}$ is the real market return for stock index $s$ at time $t$, and $E(\overline{\mathrm{R}})$ is the average expected return of market index in the estimations duration. $\mathrm{E}(\overline{\mathrm{R}})$ is computed as follows:

$$
E\left(\bar{R}_{s}\right)=\frac{1}{180} \sum_{-210}^{-21} R_{s}
$$

The period ( $t=-200$ to -21 ) is considered as the estimation period for normal return benchmark i.e. 200 days to 21 days pre-event period.

The daily average abnormal returns for the study period' event windows then calculated as:

$$
A A R_{\mathrm{s}, \mathrm{t}}=\sum_{i=1}^{n} A R_{s, t} / N
$$

Further, t-test is used to examine whether the event leads to an abnormal return in the stock market or not. To this end, we estimate the standard error using expected and abnormal returns data and t-statistics are estimated as:

$$
\mathrm{t} \text {-value }=\mathrm{AAR} / \mathrm{SE}
$$

To sum up, the event analysis has been made in a sequential order. First, we attempt to identify whether there is a significant impact on stock returns for the given event or not. For this purpose, Levene's test is performed. Second, the study intends to find which event window is statistically significant to influence the stock returns within a given event. For this purpose, dummy variable regression method is executed. Finally, in the third method, the study aims to identify the level of abnormal returns in the given event and event windows. For this purpose, estimation of abnormal returns is carried out by using running average method.

\section{Data Analysis and Discussions}

This study aims to examine the effect of catastrophe, namely the Nepale arthquake-2015, on stock returns in Nepalese capital market. The results from the data analysis obtained by applying the tests defined above are presented below. 


\subsection{Test of Homogeneity of Variance}

To determine the homogeneity of variances across groups, the Levene's test was performed. This statistical method presumes that variances are equal in populations from which various samples are taken. Having $p$-value less than 0.05 indicates a violation of assumption. That means variances across groups are different. Scientifically, when p-value is less than 0.05 , then it means that the event that we considered for testing has significant impact on stock returns. The catastrophic event, Nepal earthquake-2015, is assumed to have negative impacts on stock returns as bad news for market performance.

Description of the Catastrophic Event

\begin{tabular}{ll}
\hline Date of Events & Events Details \\
\hline 2072 Baisakh 12 & Kathmandu and its surroundings experience a 7.8 \\
(2015 April 25) & $\begin{array}{l}\text { magnitude earthquake killing over 8,000 people and causing } \\
\text { mass destruction. }\end{array}$ \\
\hline
\end{tabular}

The impact of this event was estimated on six event windows. For this purpose, the test of homogeneity on two groups are estimated using Levene's test. The effect of catastrophic event (earthquake) on stock returns measured by Levene's test are summarised in Table 1.

Table 1

Results for Effects of Catastrophe on Stock Returns

\begin{tabular}{lll}
\hline Event Windows & Levene's test value & P-value \\
\hline Window $1(-10,-1)$ & 0.671 & 0.413 \\
Window $2(0,+10)$ & 1.519 & 0.218 \\
Window $3(+2,+10)$ & 0.072 & 0.788 \\
Window $4(-10,+10)$ & 0.112 & 0.738 \\
Window $5(-5,+5)$ & 1.195 & 0.274 \\
Window $6(-3,+3)$ & $3.205^{*}$ & $0.074^{*}$ \\
\hline
\end{tabular}

Note. Test of homogeneity of variance on stock returns at catastrophic event and different event windows

As presented in Table 1, Levene's test of homogeneity indicated that the significant impact of the event was observed only in the event window $(-3,+3)$ at the $90 \%$ confidence interval for the difference, i.e. $p<0.10$. For others, variances across groups were not statistically different viewing at confidence interval of $95 \%$ or $p>$ 0.05 . Non-significance of $p$-values suggested that variances between normal market returns and returns on different event windows were approximately equal (Burns \& Burns, 2008). Such evidence proved that the stock returns between the groups were not different and had no impact on the stock returns due to Nepal Earthquake - 2015. The results contradicts the findings made by Shelor, Anderson, and Cross (1990) who investigated the effect of the 1989 California Earthquake on firms' stock value, 
and found that the firms operating in the region affected by the earthquake had a negative and statistically significant return on stock.

\subsection{Dummy Variable Regression Results}

Here, the impact of catastrophic event i.e., Nepal earthquake-2015, on stock returns has been analysed using dummy variables for the different event windows. Table 2 summarises the results of regressing using dummy variables for each event.

Table 2

Impact of Catastrophic Event, Nepal Earthquake-2015, on Stock Market

Model: OLS, using observations 2014/06/15-2015/05/27 ( $T=204$ )

Dependent variable: Stock Returns (SR)

\begin{tabular}{lllll}
\hline & $\begin{array}{l}\text { Slope } \\
\text { Coefficient }\end{array}$ & Standard Error & t-value & p-value \\
\hline Intercept & 0.016 & 0.085 & 0.183 & 0.855 \\
W1 $(-10,-1)$ & 0.147 & 0.531 & 0.278 & 0.782 \\
W2 $(0,+10)$ & -2.834 & 1.195 & -2.372 & $0.0187^{* *}$ \\
W3 $(+2,+10)$ & 0.706 & 1.173 & 0.602 & 0.548 \\
W5 $(-5,+5)$ & -0.424 & 0.981 & -0.432 & 0.666 \\
W6 $(-3,+3)$ & 0.020 & 1.070 & 0.019 & 0.985 \\
Mean dep. var & -0.044 & Std. D. dep. var & & 1.227 \\
Sum sq. resid & 272.240 & Std. Error of reg. & 1.173 \\
R-sq. value & 0.110 & Adj. R-sq. value & & 0.087 \\
F-test(5, 198) & 4.877 & P-value(F) & & 0.0003 \\
Log-likelihood & -318.897 & Akaike crit. & 649.794 \\
Schwarz crit & 669.702 & Hannan-Quinn crit. & 657.847 \\
Rho $(\rho)$ & 0.109 & Durbin-Watson value & 1.755 \\
\hline
\end{tabular}

Table 2 shows the regression results on stock returns for different event windows. In majority, the earthquake does not have significant impact on returns of stock market. The regression outcomes of five among the six event windows are statistically insignificant as $p$-values are greater than 0.05 . Only the event window $(0,+10)$, at $5 \%$ level of significance, shows the statistically significant impact of catastrophic event on stock returns. It suggests that the event's effects start form the happening date and lasts up to 10 days. Further the negative coefficient suggests that the stock returns were negatively hit by the devastating event. As it being a natural calamity, no signalling effect has been documented.

\subsection{Estimation of Abnormal Returns in Event Windows}

The primary hypothesis addressed in this section is whether or not, the unanticipated catastrophic events on stock market received any abnormal 
returns. The daily abnormal returns of stocks during the event period and over the 6 event windows are given in Table 3.

Table 3

Abnormal Stock Returns around Event Periods

\begin{tabular}{cccc}
\hline Event Day & Expected Return $\left(\mathrm{ER}_{\mathrm{t}}\right) \%$ & Abnormal Return $\left(\mathrm{AR}_{\mathrm{t}}\right) \%$ & $\mathrm{t}$-statistic \\
\hline-10 & 0.0181 & 0.4771 & 0.3391 \\
-9 & 0.0208 & 0.5164 & 0.3670 \\
-8 & 0.0187 & -0.4104 & -0.2917 \\
-7 & 0.0163 & -0.4715 & -0.3351 \\
-6 & 0.0193 & 0.5861 & 0.4165 \\
-5 & 0.0169 & -0.4697 & -0.3338 \\
-4 & 0.0165 & -0.0996 & -0.0708 \\
-3 & 0.0165 & -0.0086 & -0.0061 \\
-2 & 0.0147 & -0.3525 & -0.2505 \\
-1 & 0.0126 & -0.4317 & -0.3068 \\
0 & -0.0030 & -3.1417 & -2.2327 \\
+1 & -0.0194 & -3.3499 & -2.3806 \\
+2 & -0.0311 & -2.4142 & -1.7157 \\
+3 & -0.0439 & -2.6660 & -1.8946 \\
+4 & -0.0413 & 0.4671 & 0.3319 \\
+5 & -0.0244 & 3.4149 & 2.4268 \\
+6 & -0.0143 & 2.0531 & 1.4590 \\
+7 & -0.0080 & 1.2571 & 0.8933 \\
+8 & 0.0042 & 2.5168 & 1.7886 \\
+9 & 0.0048 & 0.1222 & 0.0868 \\
+10 & 0.0070 & 0.4415 & 0.3138 \\
\hline
\end{tabular}

Estimated period: *ER (\%) Event Windows: ${ }^{* *}$ AAR $(\%)$

\begin{tabular}{lllllll}
\hline$(-200,-21)$ & $(-10,-1)$ & $(0,+10)$ & $(+2,+10)$ & $(-10,+10)$ & $(-5,+5)$ & $(-3,+3)$ \\
0.0235 & -0.0665 & -0.1181 & 0.5769 & -0.0935 & -0.8229 & -1.7664 \\
\hline
\end{tabular}

${ }^{*} E R=$ Expected Return,

${ }^{*} A A R=$ Average Abnormal Return

Table 3 shows market statistics for the catastrophic event of earthquake. The value 1.4071 was estimated as standard error (SE) value to calculate t-statistics. It was calculated by taking a standard deviation (sd) between expected returns and abnormal returns for the event periods. In Table 3 it is evident that the t-statistic for the event day is $-2,2327$ and significant. It indicates that the devastating event impacted the stock market. In addition, negative signs suggest that the market has responded negatively to this case. On the first, second and third days after the event, t-statistics showed substantial values, suggesting that the event negatively affected the stock market. On the fourth day of the occurrence, 
however, t-statistics were negligible, i.e. 0,3319, which showed that the market revived itself from a devastating earthquake. Other results were also insignificant, even with positive signs contradicting to the prior expectation.

The averages of abnormal stock returns (real return-expected return) on each event windows have also been estimated. The results show that the positive and highest abnormal return (0.5769) was observed for the post-event period $(+2,+10)$ compared to the pre-event $(-200,-21)$ period expected return $(0.0235)$. This suggests that the buying stocks starting from $3^{\text {rd }}$ days of event happening turns out to be profitable. The excess return to this window $(+2,+10)$ is found to be $0.57 \%$ compared to the expected return. It further, suggests that semi-strong form of market efficiency prevails in Nepalese stock market.

Our study has provided results which support many of the previous work in this area. For instance, our results suggest that Nepalese stock market was least affected by the happening of unanticipated disaster i.e. earthquake, which is consistent with the study by Barrett et al. (1987) and Ramiah (2013), which did not detect any major effects on foreign capital markets. Our findings also suggest that in the event, there is a certain propensity to overreact (which is recovered within 3 days of the event), which is consistent with the study of Malkiel (2003).

\section{Conclusion and Implications}

This study analyses the impact of Nepal Earthquake - 2015 on the Nepalese stock market. The data used includes the stocks' daily price over 15 June 2014 to 7 June 2015. The intervention analysis was based on Levene's test of homogeneity of variance, dummy variable-based regression, and estimation of abnormal returns. Results of the Levene's test indicated that Nepal Earthquake - 2015, a devastating event that had little effect on stock returns in the Nepalese market. The regression analysis also revealed that the earthquake had no robust effect on the stock market' returns in general. The results documented the event's negative and significant impact on stock returns only for the event window (0, +10 ). It means that people were going for discounting the stock prices in the market for this period. The analysis of abnormal returns showed the negative impact of the catastrophe for 3 days after the event's happening. The evidence showed that the Nepalese Stock Market revived itself from the earthquake's catastrophic event after the event's third day. The investors' abnormal returns were positive and higher for the window period $(+2,+10)$. Such results further support our claim that the market adjusts the effects within this frame. For natural calamities, like an earthquake, no signalling effects have been observed. In general, the market attempts to adjust the influences of unanticipated events in three days from the day of the event. Thus, it has shown that the stock market in Nepal is semi-strongly inefficient. 


\section{References}

Angboza, L. A., \& Ranga, N. (1996). Catastrophic shocks in the property liability insurance industry: Evidence on regulatory and contagion effects. The Journal of Risk and Insurance, 63(4), 619-637.

Barrett, W., Heuson, A., Kolb, R., \& Schropp, G. (1987). The adjustment of stock prices to completely unanticipated events. The Financial Review, 22(4), 345-354.

Beaulieu, M., Cosset, J., \& Essaddam, N. (2006). Political uncertainty and stock market returns: Evidence from the 1995 Quebec Referendum. Canadian Journal of Economics, 39(2), 621-641.

Blose, L. E., Robin, B., Marci, B., Kendis, B., \& Jerry F. (1996). Catastrophic events, contagion, and stock market efficiency: The case of the space shuttle challenger. Review of Financial Economics, 5(2), 117-129.

Bosch, J. C., \& Hirschey, M. (1989). The valuation effects of corporate name changes. Financial Management, 18(4), 64-73.

Bosch, J. C., Eckard, E. W., \& Singal, V. (1998). The competitive impact of air-crashes: Stock market evidence. Journal of Law and Economics, 41(2), 503-519.

Brooks, R. M., Patel, A., \& Su, P. (2003). How the equity market responds to unanticipated events. The Journal of Business, 76(1), 109-133.

Brown, S.J., \& Warner, J.B. (1985). Using daily stock returns: The case of event studies, Journal of Financial Economics, 14(1), 3-31.

Burns, R. B., \& Burns, R. A. (2008). Business research methods and statistics using SPSS. New Delhi: Sage Publications.

Carter, D. A., \& Simkins, B. J. (2004). The market's reaction to unexpected catastrophic events: The case of airline stock returns and September $11^{\text {th }}$ attacks. The Quarterly Review of Economics and Finance, 44(4), 539-558.

Cheng, L. T. W., \& Leung, T. Y. (2006). Revisiting the corroboration effects of earnings and dividend announcements. Accounting and Finance, 46, 221-241.

Dangol, J. (2008). Unanticipated political events and stock returns: An event study. Economic Review, 20, 86-110.

Fama, E. F. (1970). Efficient capital markets: A review of theory and empirical work. The Journal of Finance, 25(2), 383-417.

Hill, J., \& Schneeweis, T. (1983). The effect of Three Mile Island on electric utility stock prices: A note. Journal of Finance, 38(4), 1285-1292.

Hovay, A., \& John, D. (2003). The impact of Denial-of-Service attack announcements on the market value of firm. Risk Management and Insurance Review, 6(2), $97-121$.

Kalra, R., Henderson, G. V. \& Raines, G. A. (1993). Effects of the Chernobyl nuclear accident on utility share prices. Quarterly Journal of Business and Economics, 32(2), 52-77.

Karki, ... (2017). Structural equation modeling of latent variables affecting stock prices: Evidence from Nepal. Tribhuvan University Journal, 31(1-2), 25-44.

Kramer, J. K., \& Hyclak, T. (2002). Why strikes occur: Evidence from the capital markets, industrial relations, 41(1), 80-93.

Lamb, R. P. (1998). An examination of market efficiency around hurricanes. The Financial Review, 33(1), 163-172. 
MacKinlay, A. C. (1997). Event studies in economics and finance. Journal of Economic Literature, 35, 13-39

Malkiel, B.G. (2003). The efficient market hypothesis and its critics. Journal of Economic Perspectives, 17(1), 59-82.

Maloney, M. T., \& Mulherin, J. H. (2003). The complexity of price discovery in an efficient market: The stock market reaction to the challenger crash. Journal of Corporate Finance, 9(4), 453-479.

McWilliams, A., \& Siegel, D. (1997). Event studies in management research: Theoretical and empirical issues. Academy of Management Journal, 40(3), 626-657.

Papadakis, S. (2006). Financial performance of supply chains disruption: An event study. Supply Chain Manage, 71, 172-194.

Ramiah, V. (2013). Effects of the Boxing Day tsunami on the world capital markets. Review of Quantitative Finance and Accounting, 40(2), 383-401.

Shelor, R. M., Anderson, D. C., \& Cross, M. L. (1990). The impact of California earthquake on real estate firms stock value. The Journal of Real Estate Research, 5(3), 335-340.

Syed, A. M., \& Bajwa, I. A. (2018). Earnings announcements, stock price reaction and market efficiency - the case of Saudi Arabia. International Journal of Islamic and Middle Eastern Finance and Management, 11(3), 416-431.

Zakaria, F. M., \& Aziz, H. B. A. (2019). The impact of unanticipated political events on stocks market returns: Empirical evidence from Saudi Arabia. International Journal of Islamic Business Ethics, 4(2), 659-675.

\section{Funding}

The author states that no funding or financial support was received for carrying out the research.

\section{Conflict of interest}

The author declares to have no conflict of interest in the research work. 